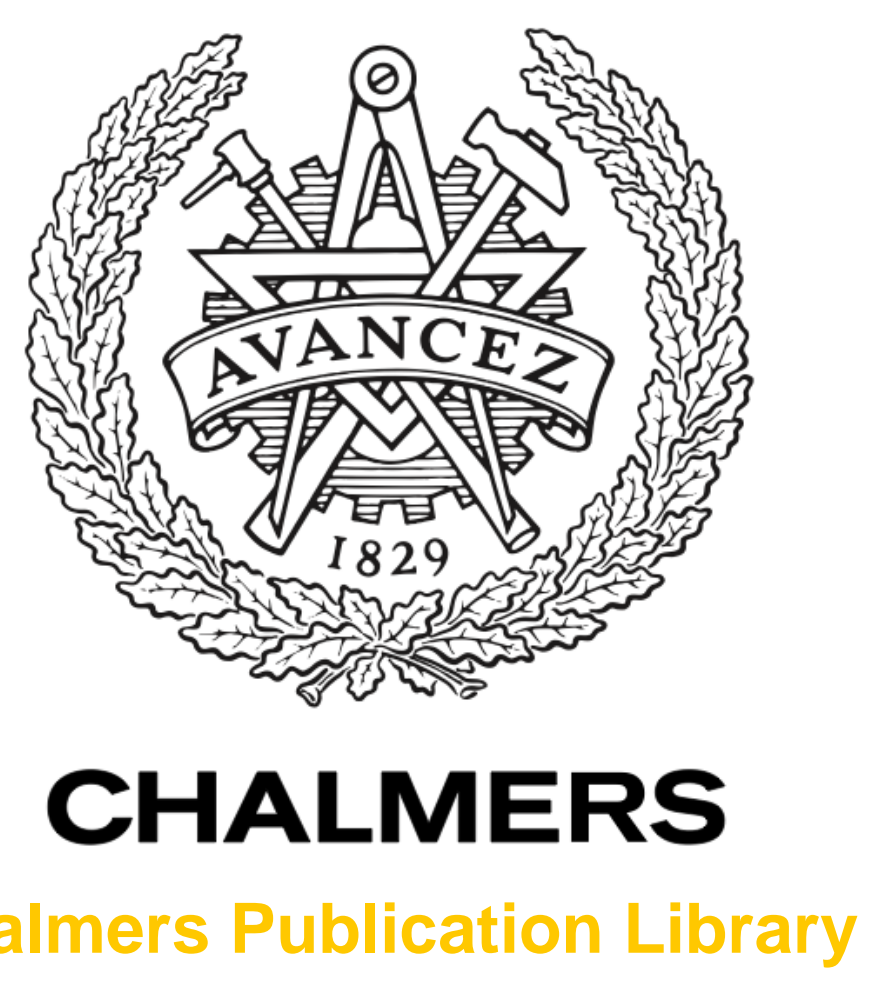

\title{
Anchorage length of near-surface mounted fiber-reinforced polymer bars for concrete strengthening - Experimental investigation and numerical modeling
}

This document has been downloaded from Chalmers Publication Library (CPL). It is the author's version of a work that was accepted for publication in:

\section{ACI Structural Journal}

Citation for the published paper:

De Lorenzis, L. ; Lundgren, K. ; Rizzo, A. (2004) "Anchorage length of near-surface mounted fiber-reinforced polymer bars for concrete strengthening - Experimental investigation and numerical modeling". ACI Structural Journal, vol. 101(2), pp. 269-278.

Downloaded from: http://publications.lib.chalmers.se/publication/1772

Notice: Changes introduced as a result of publishing processes such as copy-editing and formatting may not be reflected in this document. For a definitive version of this work, please refer to the published source. Please note that access to the published version might require a subscription. 


\title{
ANCHORAGE LENGTH OF NEAR-SURFACE MOUNTED FRP BARS FOR CONCRETE STRENGTHENING - EXPERIMENTAL INVESTIGATION AND NUMERICAL MODELING
}

\author{
Laura De Lorenzis ${ }^{1}$, Karin Lundgren ${ }^{2}$, Andrea Rizzo $^{3}$
}

\begin{abstract}
Near-surface mounted (NSM) fiber-reinforced polymer (FRP) bars are being increasingly recognized as a valid alternative to externally bonded FRP laminates for enhancing flexural and shear strength of deficient concrete, masonry and timber members. Ultimate capacity and service performance of strengthened members are deeply influenced by the bond characteristics of the strengthening system on which, in the case of NSM bars, limited data is available to date. This paper follows up to previous investigations on the mechanics of bond of NSM bars to concrete. Experimental results completing a previous test series are reported and discussed, and a global evaluation of results of three different test series is attempted. A three-dimensional finite element model for bond of NSM reinforcement is proposed and calibrated on the basis of some experimental results.
\end{abstract}

\section{INTRODUCTION AND OBJECTIVE}

In recent years, strengthening technologies for reinforced concrete structures using fiberreinforced polymer (FRP) composites have been gaining widespread interest and growing acceptance in the civil engineering industry. In this context, near-surface mounted (NSM) FRP bars are now emerging as a promising technique. FRP bars are installed by grooving the surface of the member and embedding the bars in the grooves with an appropriate binder.

Bond between the external reinforcement and the existing substrate is a critical factor for the efficiency of NSM FRP reinforcement. For this reason, some of the first investigations on the topic have specifically addressed the issue of bond (for a review, see [1]) using different test methods. A modified direct pull-out specimen was recently developed by the authors, keeping the practical advantages of direct pull-out specimens while minimizing the problem of eccentricity inherent to the previous test setups. Using this type of specimen, experimental tests were carried out to investigate the influence of the most significant variables on the bond behavior of NSM FRP bars and some results were presented in a previous publication [2]. This paper presents test results obtained on additional 34 specimens, focusing on the specimen behavior and failure mode and on the qualitative influence of the test variables. A global evaluation of the experimental data obtained from three extensive test series is also attempted.

A three-dimensional finite element model for bond of NSM reinforcement is proposed, accounting for the presence of two interfaces, and calibrated on the basis of some experimental results. Analytical modeling of test results is reported in [3].

\footnotetext{
${ }^{1}$ Corresponding author. Assist. Prof., University of Lecce, Dept. of Innovation Engineering, Via per Monteroni, 73100 Lecce - Italy

${ }^{2}$ Assist. Prof., Chalmers Univ. of Technology, Dept. of Structural Engineering, SE-412 96 Göteborg - Sweden

${ }^{3}$ Graduate student, Univ. of Lecce, Dept. of Innovation Engineering, Via per Monteroni, 73100 Lecce - Italy
} 


\section{RESEARCH SIGNIFICANCE}

The technology of NSM FRP bars, in some cases, presents substantial advantages with respect to externally bonded laminates. Some of these are the faster installation (as no surface preparation beside grooving is necessary), the possibility to anchor the bars in elements adjacent to the strengthened one, the better fire performance, and the protection from mechanical and environmental damage in negative moment regions. The bond behavior of NSM bars is of crucial importance for the effectiveness of this technology, and needs investigation in order to develop a safe design approach for NSM strengthening.

\section{EXPERIMENTAL INVESTIGATION}

\section{Test Program}

The specimen used for this investigation, developed in [2], is shown in Figure 1. It consists of a C-shaped concrete block with a square groove in the middle for embedment of the NSM bar. The applied load is reacted by means of four steel threaded bars inserted into a stiffened steel plate.

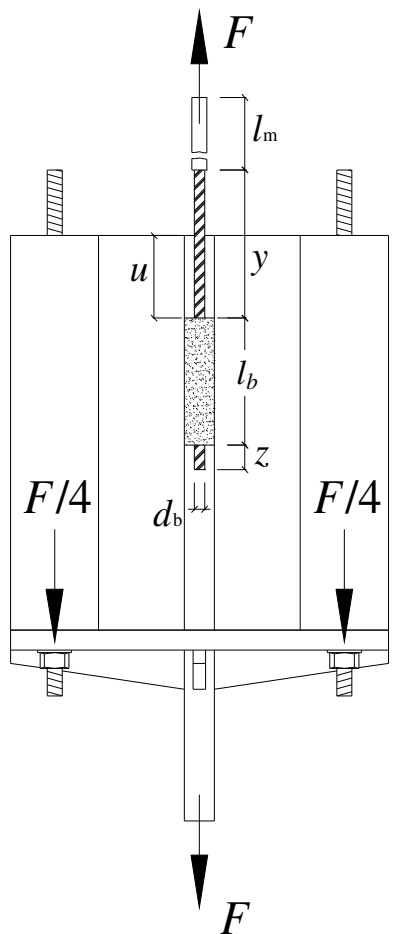

(a) Front View
Dimensions in $\mathrm{mm}$

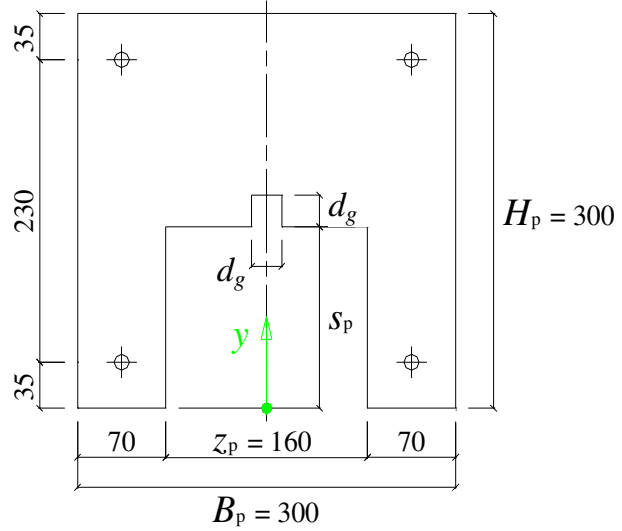

(b) Top View

Figure 1. Test specimen 
The test variables were: groove-filling material (epoxy paste and a cement-based expansive paste), bonded length (ranging from 4 to 24 times the nominal bar diameter), groove size (ranging from 1.24 to 2.50 times the actual bar diameter), and surface configuration of the bar (spirally-wound and ribbed), for a total of 34 specimens (see Table 1). The specimen code in Table 1 refers to the following variables: bar type - groove size - bonded length - groove filling material. For instance, specimen CR3/k1.33/104-e has a carbon FRP (CFRP) ribbed No. 3 bar (nominal diameter $9.5 \mathrm{~mm}$ ), with a groove size equal to 1.33 times the actual bar diameter, a bonded length equal to 4 times the nominal bar diameter, and epoxy as groove filler. This code structure will be used for specimens of previous tests series, when referenced.

Table 1. Test Program

\begin{tabular}{|c|c|c|c|c|c|c|}
\hline Specimen Code & Bar Type & $\begin{array}{l}\text { Filling } \\
\text { Material }\end{array}$ & $\begin{array}{l}\text { Groove } \\
\text { Size } d_{g} \\
(\mathrm{~mm})\end{array}$ & $\begin{array}{c}\text { Nominal/ } \\
\text { Actual } d_{b} \\
(\mathrm{~mm})\end{array}$ & $k$ & $\begin{array}{l}\text { Bonded } \\
\text { Length } l_{b} \\
\left(\mathrm{n}^{\circ} \text { of }\right. \\
\left.\text { nominal } d_{b}\right)\end{array}$ \\
\hline CR3/k1.33/104-e & \multirow{6}{*}{$\begin{array}{l}\text { Ribbed/ } \\
\text { CFRP }\end{array}$} & \multirow{21}{*}{$\begin{array}{l}\text { Epoxy } \\
\text { paste }\end{array}$} & 15 & \multirow{6}{*}{$9.5 / 11.3$} & 1.33 & \multirow{3}{*}{ 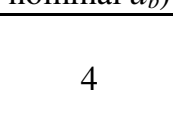 } \\
\hline CR3/k1.59/104-e & & & 18 & & 1.59 & \\
\hline CR3/k2.12/104-e & & & 24 & & 2.12 & \\
\hline CR3/k1.24/124-e & & & 14 & & 1.24 & \multirow{3}{*}{24} \\
\hline CR3/k1.59/124-e & & & 18 & & 1.59 & \\
\hline CR3/k2.12/124-e & & & 24 & & 2.12 & \\
\hline GR3/k1.36/104-e & \multirow{6}{*}{$\begin{array}{l}\text { Ribbed/ } \\
\text { GFRP }\end{array}$} & & 15 & \multirow{6}{*}{$9.5 / 11.0$} & 1.36 & \multirow{3}{*}{4} \\
\hline GR3/k1.64/104-e & & & 18 & & 1.64 & \\
\hline GR3/k2.18/104-e & & & 24 & & 2.18 & \\
\hline GR3/k1.27/124-e & & & 14 & & 1.27 & \multirow{3}{*}{24} \\
\hline GR3/k1.64/124-e & & & 18 & & 1.64 & \\
\hline GR3/k2.18/124-e & & & 24 & & 2.18 & \\
\hline SW/k1.50/104-e & \multirow{9}{*}{$\begin{array}{l}\text { Spirally } \\
\text { wound/ } \\
\text { CFRP }\end{array}$} & & 12 & \multirow{9}{*}{$7.5 / 8.0$} & 1.50 & \multirow{3}{*}{4} \\
\hline SW/k2.00/104-e & & & 16 & & 2.00 & \\
\hline SW/k2.50/104-e & & & 20 & & 2.50 & \\
\hline $\mathrm{SW} / \mathrm{k} 1.50 / 112-\mathrm{e}$ & & & 12 & & 1.50 & \multirow{3}{*}{12} \\
\hline SW/k2.00/112-e & & & 16 & & 2.00 & \\
\hline SW/k2.50/112-e & & & 20 & & 2.50 & \\
\hline SW/k1.50/124-e & & & 12 & & 1.50 & \multirow{3}{*}{24} \\
\hline SW/k2.00/124-e & & & 16 & & 2.00 & \\
\hline SW/k2.50/124-e & & & 20 & & 2.50 & \\
\hline CR3/k1.59/104-c & \multirow{2}{*}{$\begin{array}{l}\text { Ribbed/ } \\
\text { CFRP }\end{array}$} & \multirow{13}{*}{$\begin{array}{c}\text { Cement } \\
\text { paste }\end{array}$} & 18 & \multirow{2}{*}{$9.5 / 11.3$} & 1.59 & \multirow{2}{*}{4} \\
\hline CR3/k2.21/104-c & & & 25 & & 2.21 & \\
\hline GR3/k1.64/104-c & \multirow{2}{*}{$\begin{array}{l}\text { Ribbed/ } \\
\text { GFRP }\end{array}$} & & 18 & \multirow{2}{*}{$9.5 / 11.0$} & 1.64 & \multirow{2}{*}{4} \\
\hline GR3/k2.27/104-c & & & 25 & & 2.27 & \\
\hline SW/k1.50/104-c & \multirow{9}{*}{$\begin{array}{l}\text { Spirally } \\
\text { wound/ } \\
\text { CFRP }\end{array}$} & & 12 & \multirow{9}{*}{$7.5 / 8.0$} & 1.50 & \multirow{3}{*}{4} \\
\hline SW/k2.00/104-c & & & 16 & & 2.00 & \\
\hline SW/k2.50/104-c & & & 20 & & 2.50 & \\
\hline SW/k1.50/112-c & & & 12 & & 1.50 & \multirow{3}{*}{12} \\
\hline SW/k2.00/112-c & & & 16 & & 2.00 & \\
\hline SW/k2.50/112-c & & & 20 & & 2.50 & \\
\hline SW/k1.50/124-c & & & 12 & & 1.50 & \multirow{3}{*}{24} \\
\hline $\mathrm{SW} / \mathrm{k} 2.00 / 124-\mathrm{c}$ & & & 16 & & 2.00 & \\
\hline SW/k2.50/124-c & & & 20 & & 2.50 & \\
\hline
\end{tabular}



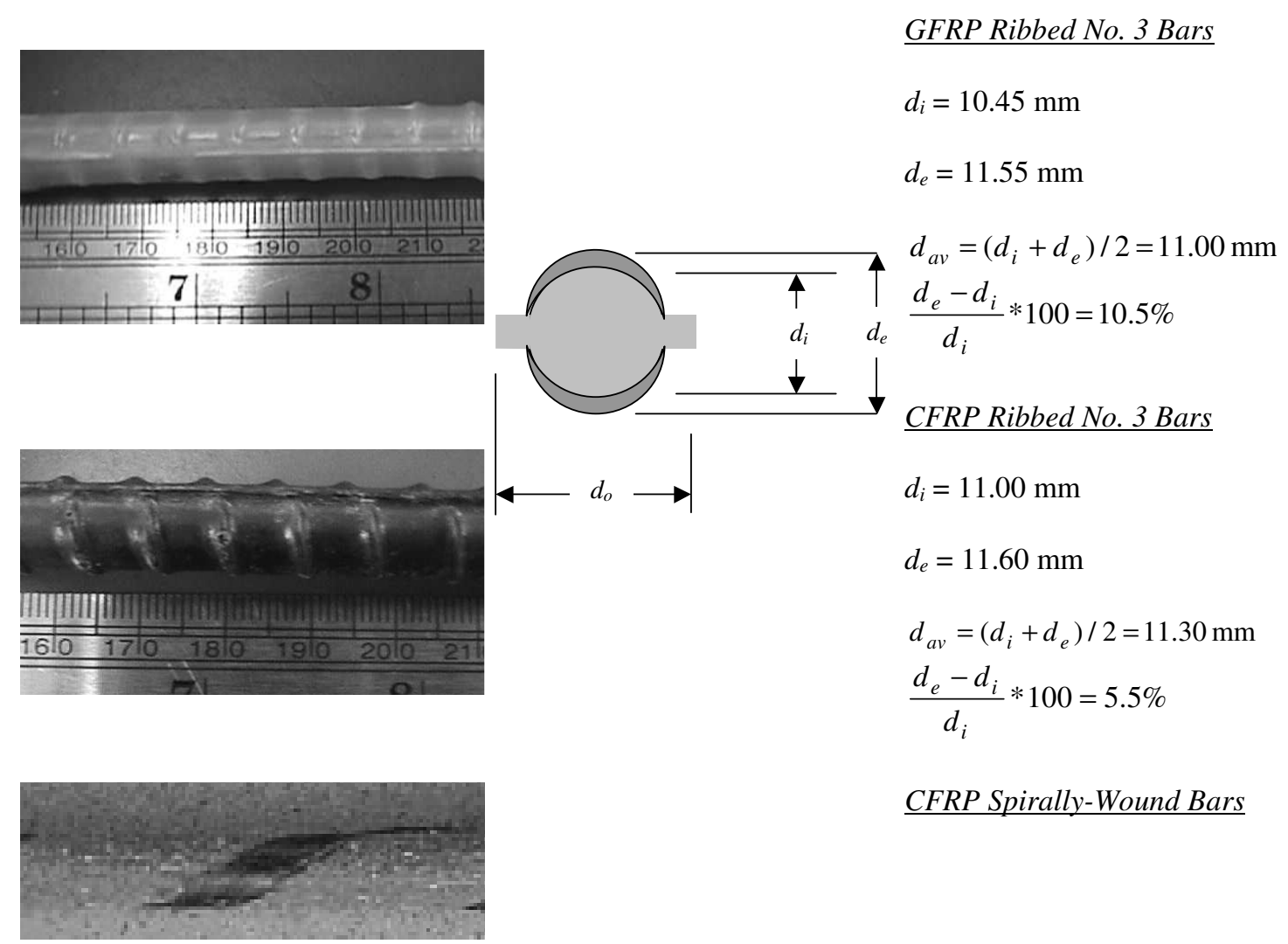

CFRP Spirally-Wound Bars

Figure 2. Types of bar used in the experiments

These specimens were added to a previous series of 36 other specimens [2], the only difference between the two sets being the groove surface condition. In the previous specimens, the grooves were pre-formed, therefore, their lateral surfaces were smooth. The specimens described in this paper had a rough groove surface, obtained by cutting the hardened concrete with a concrete saw. Hence, the groove surface condition can be considered an additional variable.

All types of bars used in the experiments are shown in Figure 2. For the purpose of computing the bonded length as a multiple of the bar diameter, and for computation of the bond stress and strength at the interface between bar and groove-filling material, the nominal diameter was used, which is the dimension of interest in the design process. Conversely, for the purpose of computing the groove size as a multiple of the diameter, the actual dimensions of the bar are significant. The groove-size-to-actual-bar-diameter ratio has been termed $k$ and reported in Table 1. Such parameter (related to the cover-thickness-to-bar-diameter ratio) has similar significance to the cover-thickness-to-bar-diameter ratio in the context of bond of internal reinforcement in concrete [4], as also shown in [3].

Spirally-wound and ribbed bars had a nominal diameter of $7.5 \mathrm{~mm}$ and $9.5 \mathrm{~mm}$, respectively. The spirally-wound bars had a superficial sand covering, intended to improve the bond behavior. Their actual diameter was approximately $8 \mathrm{~mm}$. Ribbed bars had a surface deformation pattern closely resembling that of steel deformed rebars, as visible from Figure 2. For these bars, the figure reports the average cross-sectional dimensions obtained from several measurements on sample bars. A conventional diameter was computed as the average between the maximum and minimum diameters obtained by including and excluding the rib height on both sides of the core $\left(d_{i}\right.$ and $\left.d_{e}\right)$ and taken as "actual" diameter. Such diameter, reported in 
Figure 2 and Table 1, is $16 \%$ and 19\% greater than the nominal diameter for GFRP and CFRP ribbed bars, respectively. Also indicated in Figure 2 is the ratio of the measured total rib height on the two sides of the core to the core diameter. This gives an idea of the protrusion of the ribs, which affects considerably the bond behavior. GFRP bars have more pronounced ribs than CFRP.

\section{Material Properties}

The concrete had an average compressive strength of $22 \mathrm{MPa}$, determined from ASTM-C39 standard concrete cylinders, and a tensile strength of $2.2 \mathrm{MPa}$, calculated according to the CEB-FIP MC90 [5] as 90\% of the experimental splitting strength obtained on 150x300-mm cylinders. The maximum size of aggregate was $15 \mathrm{~mm}$. The epoxy paste had a direct tensile strength of $28 \mathrm{MPa}$ evaluated according to ASTM D 638M, a compressive strength of $68 \mathrm{MPa}$ and an elastic modulus of about $6000 \mathrm{MPa}$ according to ASTM D 695M, and a 0.3 Poisson's coefficient. The cement paste had a bending tensile strength of $6.3 \mathrm{MPa}$, a compressive strength of $38 \mathrm{MPa}$ and a compressive elastic modulus of about $5500 \mathrm{MPa}$, according to the Italian standard UNI ENV 196/1. The ribbed GFRP bars had $873 \mathrm{MPa}$ tensile strength and $37.17 \mathrm{GPa}$ Young's modulus, the ribbed CFRP bars had $2014 \mathrm{MPa}$ tensile strength and 109.27 GPa Young's modulus, and the spirally wound CFRP bars had $2214 \mathrm{MPa}$ tensile strength and $174.71 \mathrm{GPa}$ Young's modulus. For more details about material characterization, see [1].

\section{Specimen Preparation and Testing}

After hardening of the concrete, the grooves were saw-cut and then air blasted to remove the powdered concrete produced by cutting. Then, either the epoxy paste was prepared by mixing the two components in 2:1 proportion by volume, or the cement paste was obtained by mixing water and cement in 0.32 proportion by weight. The groove was filled half-way and the bar was then positioned and lightly pressed. More material was applied if needed and the surface was leveled. For specimens with cement-filled grooves, the slots were saturated with water before application of the bars in order to obtain a good performance of the paste. Care was taken to ensure adequate wetting of both concrete and cement paste during at least the first week of hardening of the paste. In all specimens, plastic spacers were used to control the positioning of the bars and ensure that they were situated at the center of the groove. This allowed consistent thickness of the cover and a more accurate comparison between experimental results and analytical predictions.

The specimen was instrumented with two LVDTs, to monitor slip of the NSM bar with respect to the concrete at the loaded end and the free end of the bonded length. Testing was conducted in displacement-control mode on a $200-\mathrm{kN}$ universal testing machine with a 0.2 $\mathrm{mm} / \mathrm{min}$ cross-head displacement rate. 
Table 2. Test Results

\begin{tabular}{|c|c|c|c|c|c|c|}
\hline Spec. Code & $\begin{array}{l}P_{\max } \\
(\mathrm{kN}) \\
\end{array}$ & $\begin{array}{c}P_{\max } / P_{u} \\
(\%)\end{array}$ & $\begin{array}{c}\tau_{\text {avu }} \\
(\mathrm{MPa})\end{array}$ & \begin{tabular}{|l|}
$\left(s_{l e}\right)_{\text {lim }}$ \\
$(\mathrm{mm})$
\end{tabular} & $\begin{array}{c}\left(s_{f e}\right)_{\lim } \\
(\mathrm{mm})\end{array}$ & Failure Mode \\
\hline \multicolumn{7}{|c|}{ Specimens with epoxy-filled grooves } \\
\hline CR3/k1.33/104-e & 13.12 & 9.2 & 11.24 & 0.304 & 0.102 & Splitting \\
\hline CR3/k1.59/104-e & 17.91 & 12.5 & 15.35 & 0.287 & 0.034 & Splitting \\
\hline CR3/k2.12/104-e & 19.33 & 13.5 & 16.56 & 1.549 & 0.206 & Splitting \\
\hline CR3/k1.24/124-e & 52.16 & 36.5 & 7.45 & 2.128 & 0.372 & Splitting \\
\hline CR3/k1.59/124-e & 50.80 & 35.6 & 7.25 & 0.454 & \begin{tabular}{|l|}
0.152 \\
\end{tabular} & Splitting \\
\hline CR3/k2.12/124-e & 66.47 & 46.6 & 9.49 & 0.560 & 0.198 & Splitting \\
\hline GR3/k1.36/104-e & 10.67 & 17.2 & 9.14 & 0.125 & 0.024 & Splitting \\
\hline GR3/k1.64/104-e & 14.68 & 23.7 & 12.58 & N/A & N/A & Splitting \\
\hline GR3/k2.18/104-e & 14.57 & 23.5 & 12.48 & 1.224 & 0.130 & Splitting \\
\hline GR3/k1.27/124-e & 26.45 & 42.7 & 3.78 & 1.457 & 0.016 & Splitting \\
\hline GR3/k1.64/124-e & 39.55 & 63.9 & 5.65 & 1.864 & 0.000 & Splitting \\
\hline GR3/k2.18/124-e & 32.04 & 51.8 & 4.58 & 1.310 & 0.068 & Splitting \\
\hline SW/k1.50/104-e & 12.75 & 12.6 & 18.04 & 0.228 & 0.228 & Splitting \\
\hline SW/k2.00/104-e & 14.67 & 14.4 & 20.76 & 0.266 & 0.266 & Splitting \\
\hline SW/k2.50/104-e & 15.50 & 15.3 & 21.93 & 0.181 & \begin{tabular}{|l|}
0.181 \\
\end{tabular} & Splitting + Pull-out \\
\hline SW/k1.50/112-e & 28.86 & 28.4 & 13.61 & N/A & 0.190 & Splitting \\
\hline SW/k2.00/112-e & 25.62 & 25.2 & 12.08 & N/A & 0.158 & Splitting \\
\hline SW/k2.50/112-e & 37.27 & 36.7 & 17.57 & 0.385 & 0.168 & Splitting \\
\hline SW/k1.50/124-e & 41.32 & 40.7 & 9.74 & \begin{tabular}{|l|}
0.398 \\
\end{tabular} & 0.020 & Splitting \\
\hline SW/k2.00/124-e & 60.00 & 59.0 & 14.15 & 0.883 & \begin{tabular}{|l|}
0.154 \\
\end{tabular} & Splitting \\
\hline SW/k2.50/124-e & 67.43 & 66.4 & 15.90 & 1.201 & 0.284 & Splitting + Pull-out \\
\hline \multicolumn{7}{|c|}{ Specimens with cement-filled grooves } \\
\hline CR3/k1.59/104-c & 11.01 & 7.7 & 9.66 & 0.304 & 0.304 & Splitting \\
\hline CR3/k2.21/104-c & 7.31 & 5.1 & 6.41 & 0.902 & 0.902 & Splitting \\
\hline GR3/k1.64/104-c & 9.10 & 14.6 & 7.98 & 0.129 & 0.092 & Splitting \\
\hline GR3/k2.27/104-c & 9.44 & 15.2 & 8.28 & 0.392 & 0.102 & Splitting \\
\hline SW/k1.50/104-c & 4.71 & 4.6 & 6.67 & 0.246 & 0.246 & Splitting \\
\hline SW/k2.00/104-c & N/A & N/A & N/A & N/A & N/A & N/A \\
\hline SW/k2.50/104-c & N/A & N/A & N/A & N/A & $\mathrm{N} / \mathrm{A}$ & $\mathrm{N} / \mathrm{A}$ \\
\hline $\mathrm{SW} / \mathrm{k} 1.50 / 112-\mathrm{c}$ & 8.86 & 8.7 & 4.18 & 0.252 & 0.104 & Splitting \\
\hline $\mathrm{SW} / \mathrm{k} 2.00 / 112-\mathrm{c}$ & 10.45 & 10.3 & 4.93 & 0.040 & 0.022 & Splitting + Pull-out \\
\hline SW/k2.50/112-c & 7.80 & 7.7 & 3.68 & 0.194 & 0.064 & $\begin{array}{l}\text { Pull-out } \\
\end{array}$ \\
\hline SW/k1.50/124-c & 22.68 & 22.3 & 5.35 & 0.292 & 0.082 & Splitting \\
\hline SW/k2.00/124-c & 27.19 & 26.8 & 6.41 & 0.355 & 0.076 & Splitting + Pull-out \\
\hline SW/k2.50/124-c & 20.14 & 19.8 & 4.75 & 0.301 & 0.096 & Pull-out \\
\hline
\end{tabular}

$\tau_{a v u}=$ Average bond stress at the interface between bar and groove-filler at failure; $\left(s_{l e}\right)_{l i m}=$ Loaded-end slip corresponding to the peak load;

$\left(s_{f e}\right)_{\text {lim }}=$ Free-end slip corresponding to the peak load; N/A = Not available.

\section{Test Results}

The main test results are reported in Table 2 and Figures 3-5, and are described as follows.

\section{Specimens with epoxy-filled grooves}

Failure occurred for all specimens by cracking of the concrete surrounding the groove accompanied by formation of splitting cracks in the epoxy cover (briefly indicated as "splitting"). The sequence of stages observed in the behavior of most specimens is as follows (Figure 3): (a) at low load levels (typically up to about $50 \%$ of the ultimate load), no cracks 
are visible on epoxy and concrete; (b) for a load close to $50 \%$ of the ultimate load, a typical crackling noise reveals the onset of internal microcracking in the epoxy; (c) soon after beginning of the noise, a longitudinal splitting crack becomes visible in the epoxy cover at the bar loaded end, but no cracking is yet visible in the concrete surrounding the groove (Figure 3-a) (sometimes splitting is initiated by the formation at the loaded end of cracks in the epoxy inclined at approximately 45 degrees, starting from the edges of the groove and merging into a longitudinal crack); (d) the crack propagates longitudinally in the epoxy towards the bar free end; at the same time, along the portion of bonded length where the epoxy cover is already cracked, the profile of a superficial crack starts appearing in the concrete (Figure 3-b). This indicates that cracking of the epoxy relieves the circumferential stresses in the bar cover which balance the radial components of the bond stresses. Such components must then be balanced by tensile stresses in the concrete which soon exceed the concrete tensile strength and lead to the formation of cracks along inclined planes; (e) the concrete crack extends along the entire bonded length and opens up (Figure 3-c).

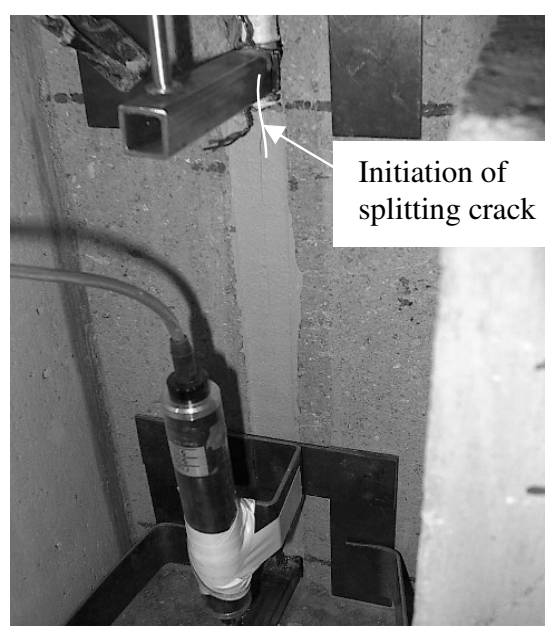

(a)

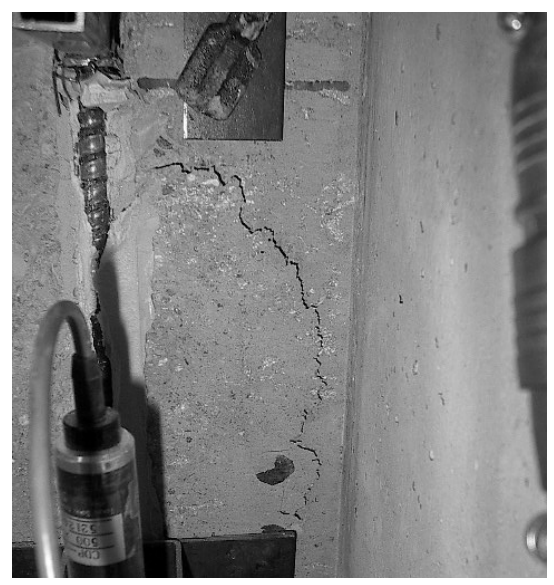

(c)

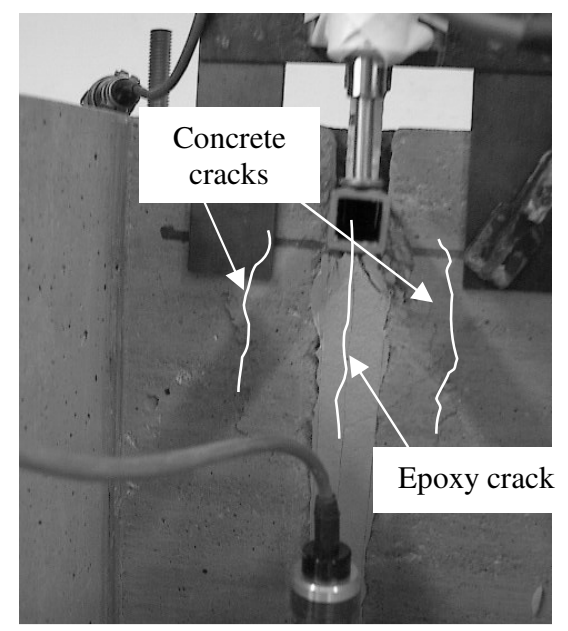

(b)

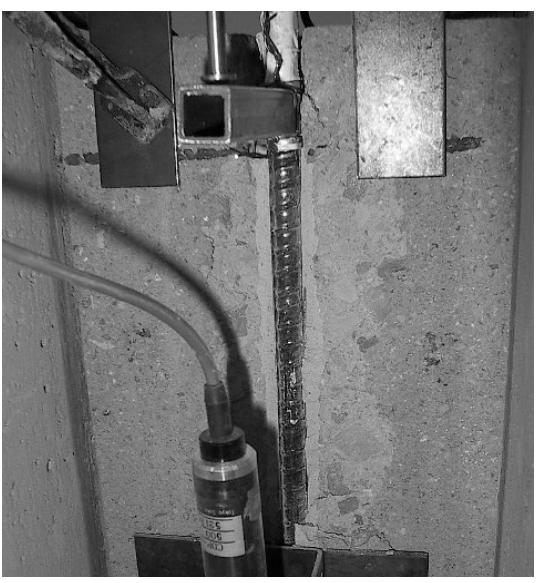

(d)

Figure 3. Typical damage and failure stages of the specimens with epoxy-filled grooves failed by splitting: formation of a longitudinal splitting crack in the epoxy cover at the bar loaded end (a); formation of inclined cracks in the concrete surrounding the groove (b); opening of the concrete cracks (c); specimen after failure (d). 
The behavior was somewhat different between specimens with different types of bars. In specimens with CFRP ribbed bars and four-diameter bonded length, after propagation of the epoxy crack and formation of the concrete crack, the load started decreasing as the concrete crack width increased. The faces separated by the crack still had some cohesion due to aggregate interlocking. Qualitatively, the average bond stress vs. slip curves of specimens CR3/104 (Figure 5-a) are similar to the curves giving the concrete tensile stress across a crack vs. the crack opening displacement (see for example [6]). This makes sense, as the average bond stress $\tau$ (which can be approximately regarded as the local bond stress for short bonded lengths) can be considered proportional to the radial pressure $p$ exerted by the bar on the surrounding cover, which in turn is balanced, in the final stage, by tensile stresses in the concrete; and the longitudinal slip is accompanied by gradual opening of the crack. In specimens with long bonded lengths, the maximum load was generally reached after propagation of the epoxy longitudinal crack and formation of the concrete crack. The cover was expelled when the ultimate cracking pattern had formed rather uniformly along the entire bonded length. Continuing the test would have probably shown a low-level residual friction due to the half perimeter of the bar still in contact with epoxy (Figure 3-d). However, the test was stopped and this phase was not recorded.

In specimens with GFRP bars, the higher relative rib area led to a more brittle joint behavior. In specimens with short bonded length, once the longitudinal crack had reached the free end, the epoxy cover was suddenly split along with a portion of the concrete surrounding the groove. The average bond stress vs. slip curve has a very steep ascending branch followed by an abrupt decrease in bond stress upon formation of the failure cracking pattern (Figure 5-b). The subsequent behavior depends on the activated mechanisms of residual strength. After complete loss of the cover, a low value of residual friction was maintained by the half perimeter of the bar still in contact with epoxy (not reported in the curve). In specimens with long bonded lengths, the maximum load was reached before the epoxy longitudinal crack (and the consequent lateral concrete crack) had propagated along the entire bonded length. At the maximum load, the cracked portion of the joint detached and the remaining part, unable to transfer the load, followed in a brittle fashion. The load dropped to a value corresponding to residual friction of the half perimeter of bar still in contact with epoxy.

The behavior of specimens with CFRP spirally-wound bars was similar (although with very different bond strength values) to that of specimens with GFRP ribbed bars, probably due to the interaction between splitting phenomena and the relative slip between bar and epoxy resulting from the weakness of the superficial sand cover. A distinct feature of these specimens, however, is that appearance of the crack profile in the concrete did not always follow immediately cracking of the epoxy. As bonded length and groove size increase, concrete cracking tends to become visible only after attainment of the maximum load. As the groove size increases, splitting failure becomes less brittle and is partially accompanied by slip at the bar-epoxy interface. This phenomenon was particularly clear in specimens $\mathrm{SW} / \mathrm{k} 2.50$, in which concrete cracking became evident only at an advanced softening stage, and splitting was accompanied by noticeable slip at the bar-epoxy interface. The latter resulted from damage of the sand covering and of the carbon fiber spirally-wound tow on the bar surface (Figure 4-a). The average bond stress vs. slip curve has a very steep ascending branch followed by an abrupt decrease in bond stress upon formation of the longitudinal crack in the epoxy, and by a frictional plateau due to residual friction between bar and epoxy (Figure 5-c). For this bar surface configuration, cracking of the epoxy cover accelerates slip at the bar - epoxy interface and this phenomenon becomes prevalent on concrete cracking, as witnessed by the late appearance of the superficial crack profile in the concrete. 


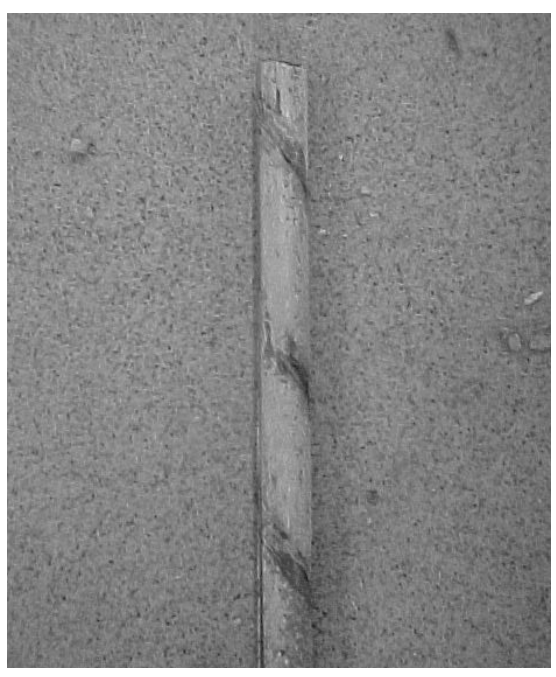

(a)

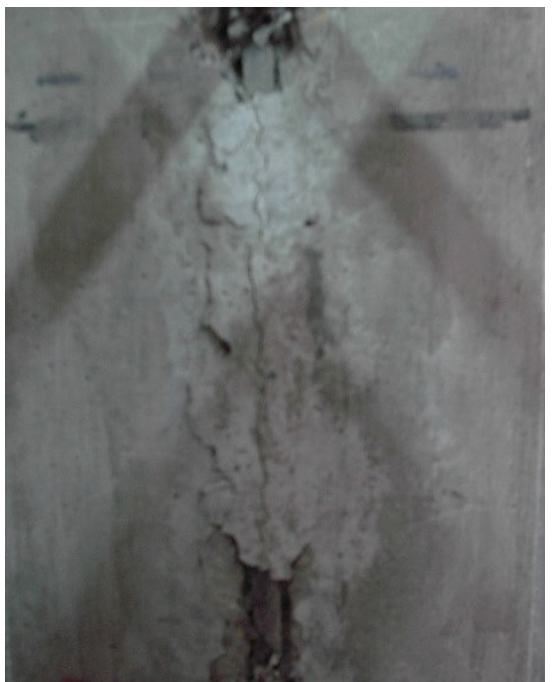

(c)
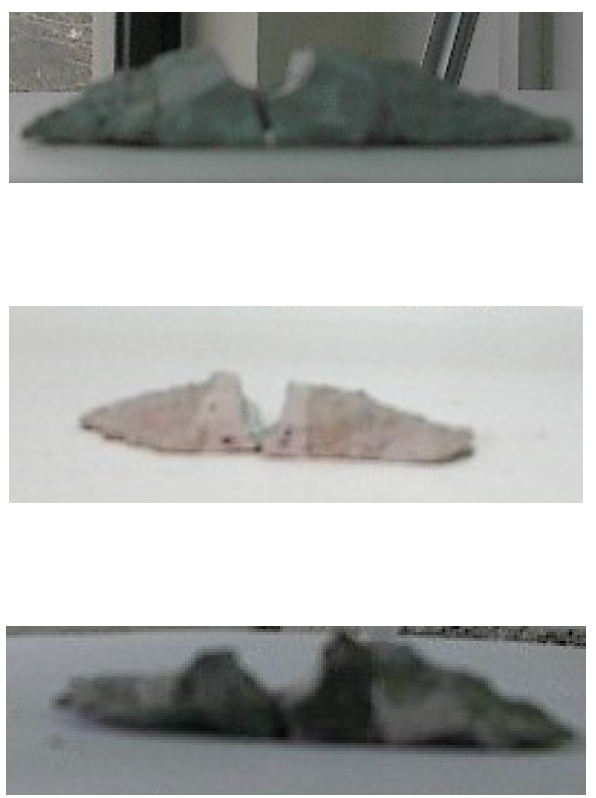

(b)

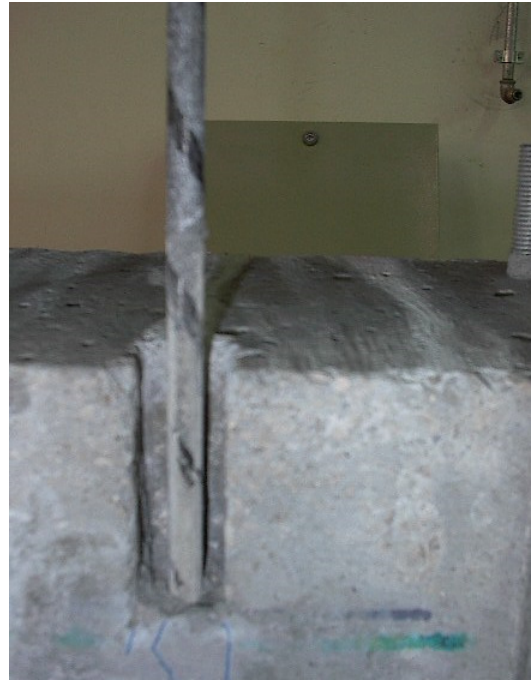

(d)

Figure 4. Pictures of the failure modes: damage of the sand cover and spiral tow on the bar surface (a); cracking pattern in the plane perpendicular to the bar axis (b); splitting failure in specimens with cementfilled grooves (c); pull-out at the bar-cement interface (d). 


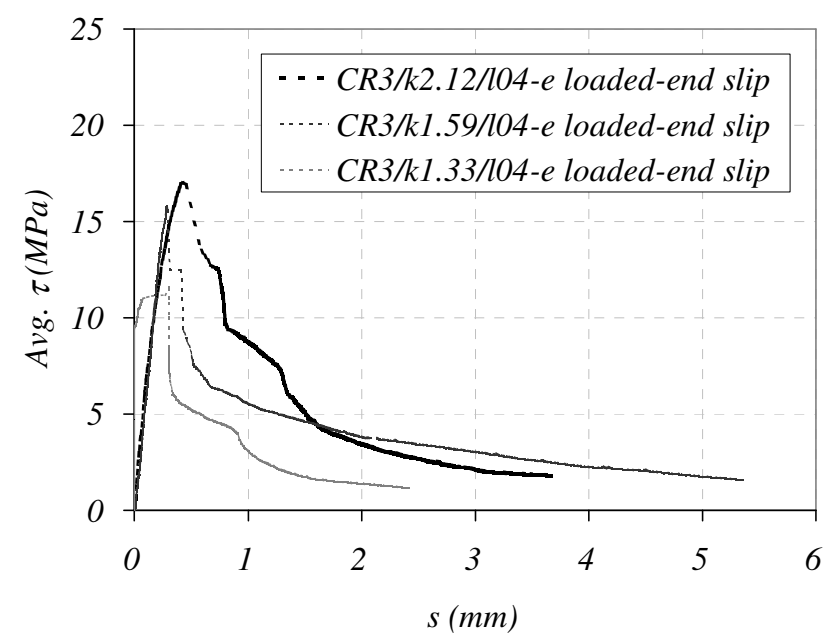

(a)

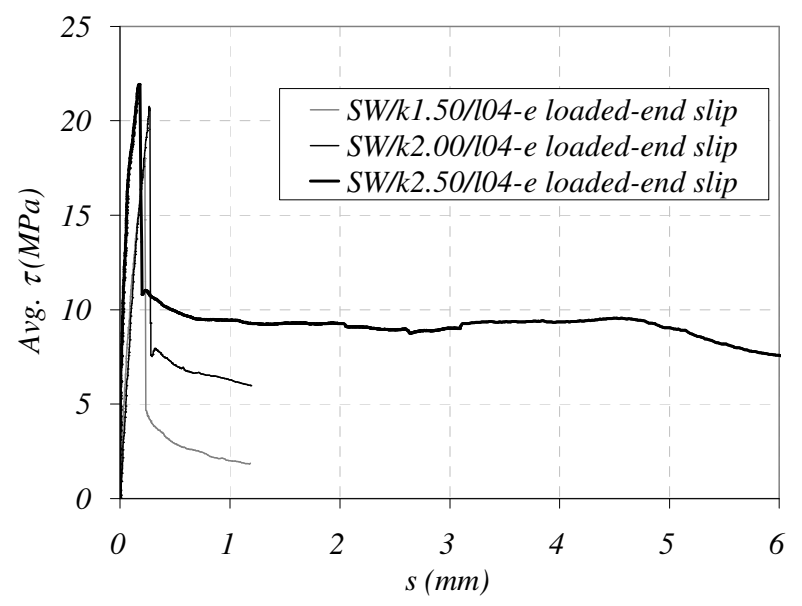

(c)

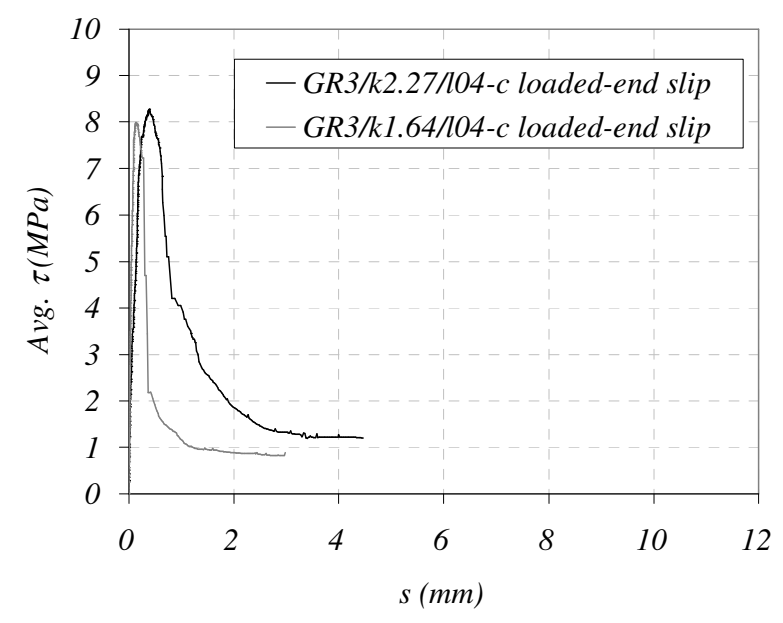

(e)

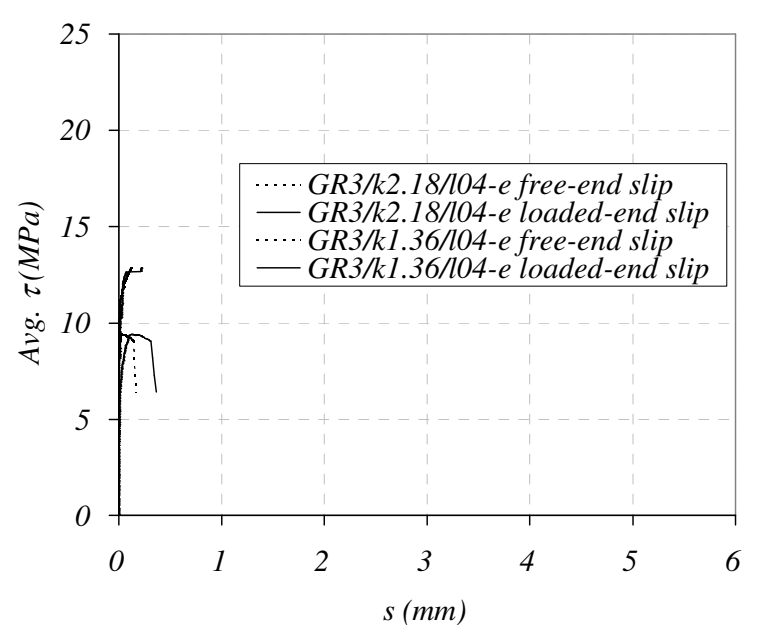

(b)

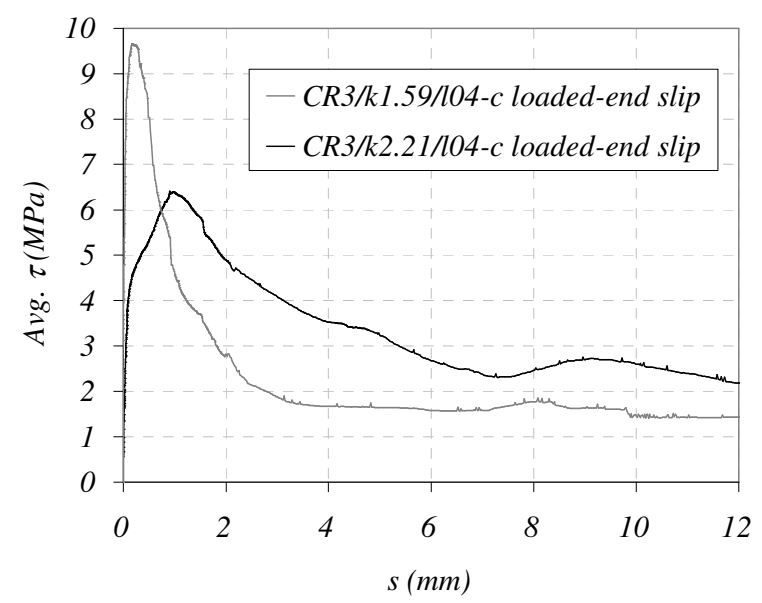

(d)

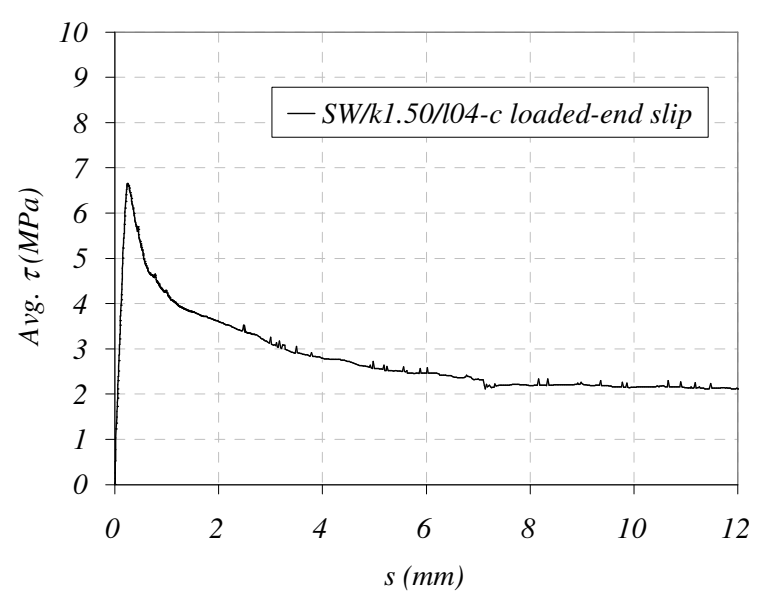

(f)

Figure 5. Average bond stress vs. slip curves of the tested specimens with short bonded length: specimens with epoxy-filled grooves and CFRP ribbed bars (a); specimens with epoxy-filled grooves and GFRP ribbed bars (b); specimens with epoxy-filled grooves and CFRP spirally-wound bars (c); specimens with cement-filled grooves and CFRP ribbed bars (d); specimens with cement-filled grooves and GFRP ribbed bars (e); specimens with cement-filled grooves and CFRP spirally-wound bars $(f)$. 
In nearly all cases, the pieces of fractured concrete were rather shallow. The fracture plane was inclined approximately 30 degrees with respect to the concrete surface, starting from the mid-plane of the groove (see Figure 4-b). This implied that, for a given $k$ value, the length of the crack profile was proportional to the bar diameter.

\section{Specimens with cement-filled grooves}

Failure occurred in most cases by splitting phenomena in the bar cover as well as in the surrounding concrete. A difference with respect to the epoxy-filled specimens is that the cement cover, upon cracking, experienced a gradual crack propagation and damage (Figure 4c) but was not always expelled from the specimen. Differences in the failure mode could be noted as the values of the test variables were varied, as follows.

Specimens with ribbed bars failed all by splitting, with significant extent of cracking of the concrete surrounding the groove. Splitting initiated by the formation in the cover at the loaded end of a longitudinal splitting crack, this then propagated longitudinally towards the free end of the joint. Appearance of the crack profile in the concrete coincided with attainment of the maximum load and was rather uniform along the bonded length. Failure was more brittle in the case of GFRP bars due to their lower modulus and higher rib protrusion.

For specimens with CFRP spirally-wound bars, a transition in failure mode was observed as the groove size increased: while joints with the smallest $k$ value failed by splitting, those with the largest $k$ failed by pull-out at the bar-cement interface with extensive damage to the sand cover of the bar (Figure 4-d). However, splitting phenomena were also observed in the portion of the joint close to the loaded end. Specimens with intermediate $k$ experienced a mixed mode between the previous two: the splitting phenomena were accompanied by slip at the barcement interface. In all cases, the splitting cracks in the concrete became visible when the maximum load was reached.

The bond-slip behavior for both splitting and pull-out failure was different from that described previously for the epoxy-filled specimens, in accordance with the different behavior of the cement cover. Upon formation of the first splitting cracks the load started to decrease gradually and the curve displayed a post-peak softening branch as in Figure 5 d-f.

\section{EFFECT OF TEST VARIABLES}

\section{Effect of Groove-Filling Material}

Specimens with cement-filled grooves had in all cases lower bond failure loads than epoxyfilled ones. This is due to the higher tensile strength of epoxy, which delays the formation of the longitudinal splitting crack in the cover and hence the phase where the normal pressure between bar and surrounding material is fully developed. The lower shear strength of the cementitious paste is also concurrent to the incidence of the pull-out failure mechanism, observed alone only in cement-filled joints. In cement-filled specimens, the grooves were saturated with water to ensure proper hardening. Nevertheless, due to the slight expansivity of the cement, longitudinal and transverse cracks in the cover were observed upon hardening, and these cracks were wider and more numerous in specimens with the largest $k$. Their presence probably affected negatively the performance of the joint during loading. 


\section{Effect of Bonded Length and Groove Size}

For a given groove depth, the ultimate load of the joint increases as the bonded length increases. However, the average bond strength decreases, due to the non-uniform distribution of the bond stresses along the bonded length. Exceptions are specimens with cement-filled grooves and spirally-wound bars, due to the more ductile bond-slip behavior. For a given bonded length, the average bond strength generally increases for increasing $k$, as the bigger cover depth delays the occurrence of splitting. However, in this test series as well as in a previous one [7] such increase was less sensitive for higher $k$ values. Moreover, in case of cement-filled grooves with spirally wound bars, the specimen with the highest $k$ value fails by pull-out at a lower load than that with the intermediate $k$, due to the pre-existing cracks.

\section{Effect of Bar Surface Configuration}

Among ribbed bars, the joint behavior was more brittle for GFRP than for CFRP bars, due to the more pronounced ribs but also to the lower modulus of elasticity. Also, the bond failure load of specimens with GFRP bars was always lower than that of specimens with CFRP bars and the same values of the remaining parameters. The difference is more pronounced on specimens with longer bonded lengths, whose average bond strength is related not only to the local bond strength but also to the ductility of the bond-slip behavior (e.g., the ultimate load of specimen CR3/k2.12/104-e was 33\% higher than that of GR3/k2.18/104-e, but the ultimate load of CR3/k2.12/124-e was 107\% higher than that of GR3/k2.18/124-e). Although ribbed and spirally-wound bars cannot be rigorously compared because of the different diameter, spirally-wound bars yielded the highest average bond strengths, for the same remaining parameters.

\section{Effect of Groove Surface Condition}

The ultimate load of specimens with smooth and rough groove surfaces with epoxy as groove filler can be compared between results of this test series and of the previous one reported in [2]. As expected, the specimens with rough grooves failed in all cases at higher load levels. However, as the local bond - slip relationship in the case of smooth grooves is more ductile than for rough grooves, the rate of increase of the bond failure load with the bonded length is higher in the case of smooth grooves [3].

\section{SUMMARY OF EXPERIMENTAL RESULTS ON BOND OF NSM FRP BARS}

As follows, results on bond of NSM FRP bars obtained in different test series are summarized. The first series is that described in [7], the second one is reported in [2], and the third series is the current one.

\section{Summary on Failure Modes}

Pull-out at the interface between bar and groove-filling material. This is the critical failure mode for sandblasted bars, provided that the groove size is sufficient to avoid splitting failure. Pull-out failure has also been encountered for spirally wound bars embedded into cement paste for the highest groove depths ( $k$ equal to 2.50 ).

Splitting. This is the critical failure mode for ribbed and spirally wound bars, at least when the groove surface is sufficiently rough to avoid failure at the interface between concrete and groove-filling material. When the $k$ ratio is very low (specimens of the first series [7] with $k=1.12 \div 1.18$ ), failure is limited to the bar cover and creates little damage in the surrounding 
concrete. For higher values of $k$, failure results from a combination of longitudinal cracking in the epoxy, and fracture of the surrounding concrete along inclined planes. In the first series, it was not possible to observe the test region during loading so to understand the progression of the cracking phenomena. However, inspection of the expelled cover fragments revealed that the epoxy was cracked longitudinally in nearly all cases. This behavior was confirmed by specimens of the third series, which displayed the progression of cracking mechanisms described previously.

Failure at the interface between concrete and groove-filling material. This mechanism is critical when the groove surface is smooth, as observed in the second test series [2]. For spirally wound bars or ribbed bars with low rib protrusion embedded into epoxy, this was the critical failure mode whenever the groove surface was smooth, independently from the value of $k$. For ribbed bars with high rib protrusion embedded into epoxy, and for all types of bars embedded into cement paste, this mechanism was critical when the groove surface was smooth but only for values of $k$ greater than a minimum value (equal to about 2.00 for GFRP bars in epoxy and to about 1.50 for all bars in cement paste). For lower $k$ values the dominant mechanism was splitting.

Shearing of the ribs on the bar surface. This was never a failure mode itself, unlike in the case of FRP ribbed bars in concrete [8-9]. However, the surface of the ribbed bars was often damaged after failure, to an extent proportional to the ultimate load sustained by the joint. It might be inferred that, if the groove size and the concrete tensile strength were large enough to raise the ultimate load of the joint, the failure mechanism might shift to sequential shearing of the ribs.

The reason this mechanism is less critical for NSM than for internal FRP reinforcement, apart from the existence of other failure mechanisms typical of the NSM configuration, is probably the low modulus of elasticity of epoxy (and of cement paste) compared to concrete. As the ribs bear against a more compliant material, their state of stress is reduced.

\section{Summary on Effect of the Test Variables}

The bar surface configuration proved to be of crucial importance for the specimen failure mode and consequently for the bond stress - slip relationship.

Among specimens with smooth grooves (second test series), the only specimens failing by splitting were those with GFRP ribbed bars (apart from the one with the biggest groove size), as a result of the higher rib protrusion. The difference was noted also among specimens with rough grooves, where the behavior of the joint was more brittle for GFRP than for CFRP bars (see previous section).

Specimens with sandblasted bars mostly failed by pull-out, at rather low values of average bond strength (between 4 and $5 \mathrm{MPa}$ for 12-diameter bonded length).

It could be concluded that the superficial pattern of FRP bars to be used as NSM reinforcement, while being sufficiently rough to avoid failure by pull-out at the bar-epoxy interface (apparently light sandblasting is not enough for this purpose and spiral winding with sanding is not always fully effective), should generate radial stresses as low as possible to delay splitting phenomena and to allow a pseudo-ductile bond - slip behavior.

When failure occurs by pull-out, the groove size does not influence the average bond strength, provided that is enough to avoid the occurrence of splitting cracks which would accelerate 
failure. A groove size equal to 1.5 times the bar diameter should be the optimum for sanblasted bars (first test series). For the other failure mechanisms, the ultimate load increases for increasing groove size. The trend of the average bond strength depends on the failure mode. When failure is at the epoxy-concrete interface, the average bond strength of significance is that at the failed interface (see the second test series). In this case, the average bond strength decreases as the groove size increases, due to the non-uniform distribution of the bond stresses along the perimeter of the groove. For splitting failure, the average bond strength of significance is that at the interface between bar and groove-filling material. This value, as shown in the first and in the present test series, increases for increasing groove size. However, the increase is less sensitive for higher $k$ values. A $k$ ratio equal to 2.0 based on the nominal bar diameter should be a recommendable choice.

The ultimate load of the joint increases as the bonded length increases. However, in practically all cases the average bond strength decreases. The rate of decrease basically depends on the brittleness of the local bond-slip relationship, which in turn is related to the primary bond mechanisms activated and to the failure mode. The specimens which most closely approached a uniform distribution of bond stresses and hence an average bond strength constant with the bonded length (in the test range) were the CR3 specimens of the first series, the specimens failed at the epoxy-concrete interface of the second series and the specimens with cement-filled grooves and spirally-wound bars of the current series.

About the effect of the groove filler, as reported previously, the ultimate load of specimens with cement-filled grooves was in all cases well lower than that of epoxy-filled specimens.

A rigorous evaluation of the influence of the epoxy properties on the bond performance is not possible. However, it is reasonable to expect that epoxies with higher tensile strengths are able to withstand higher splitting stresses and hence to guarantee higher values of bond strength. For a given tensile strength, it might be expected that a groove-filling material with lower modulus of elasticity results in a more compliant surrounding "ring" for the bar and thus in less intense local stress concentrations. This should produce a higher bond strength and a more ductile bond-slip behavior.

The effect of the groove surface condition was already examined in the previous section.

\section{FINITE ELEMENT MODELING}

\section{Introduction}

In [3], bond between NSM FRP bars and concrete is modeled analytically. The approach followed has been to "split" the three-dimensional (3D) bond problem into two distinct problems, a one-dimensional and a bidimensional one. The distribution of bond stresses along the reinforcement (that is, the bond behavior in the "longitudinal plane") can be obtained by solving the differential equation of bond, once the local bond stress vs. slip relationship is known. Such relationship in turn depends on what happens in the "transverse plane", where the cover depth and the possible presence of confining pressure are of great influence on the bond behavior.

Although analytical modeling in the "transverse" plane can give information on the influence of geometrical and mechanical parameters (such as groove size, groove-filling material and concrete tensile strength) on the upper and lower bounds of the local bond strength, such 
information is not sufficient to predict the local bond-slip relationship of the joint for different values of the aforementioned parameters. 3D finite element (FE) modeling is a means through which the analysis can be carried out at the same time in the longitudinal and in the transverse plane, and the bond behavior can be more realistically described.

A 3D FE model for bond of NSM FRP reinforcement in concrete was developed. Bond of NSM reinforcement differs from bond of internal reinforcement for the existence of two interfaces: the bar-epoxy and the epoxy-concrete interface. This is why, although models on the bond behaviour of FRP bars to concrete have already been presented (see e.g. [10] and [11]), they are not applicable to the case under examination. The presence of these two interfaces increases the number of parameters needed to characterize the global "joint" behavior and introduces new possible failure modes. A model for bond of steel reinforcement in concrete previously proposed and implemented by Lundgren [12] using the FE program Diana [13] was calibrated on the basis of some of the experimental tests presented in [2] and used for the bar-epoxy interface. The epoxy-concrete interface was modeled with a Coulomb frictional model. Note that, as calibration was conducted on specimens with epoxy-filled grooves, in the following reference will be always made to epoxy. However, everything could be equally referred to other groove fillers.

Both interfaces were modeled with interface elements (Figure 6), describing a relation between the traction $\mathbf{t}$ and the relative displacement $\mathbf{u}$. Concrete, epoxy and FRP bar were all modeled with solid elements. The features of the various models and the process of calibration are illustrated below. Finally, numerical and experimental results are compared.

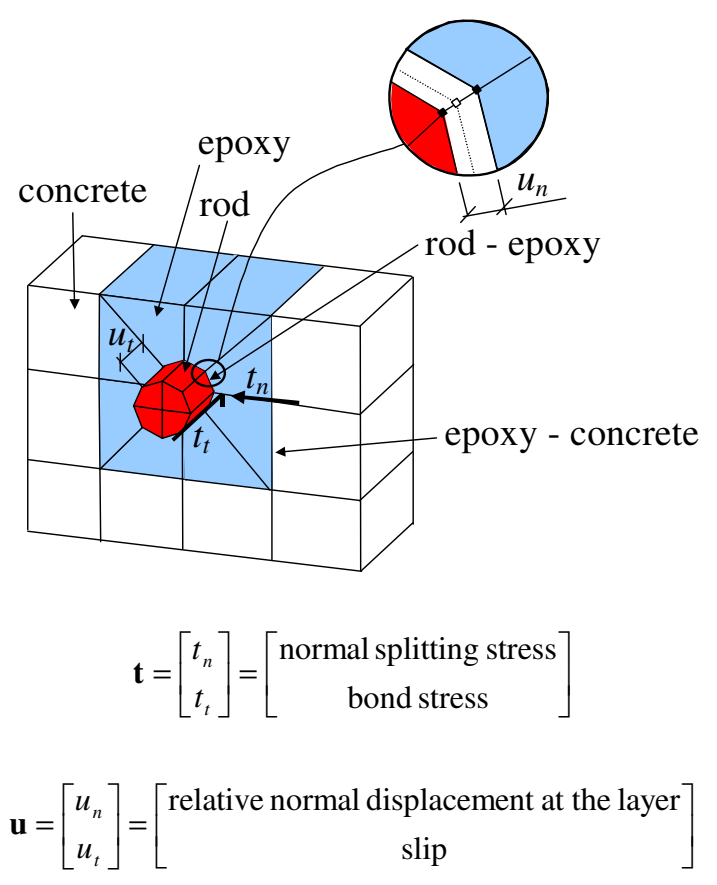

Figure 6. Modeling using solid elements and interface elements at the bar-epoxy and the epoxy-concrete surface. 


\section{Experiments Used for Calibration}

The model was calibrated for GFRP ribbed No. 3 bars (9.5-mm nominal diameter), epoxybonded to normal strength concrete in smooth grooves. Other materials, and especially bars with different surface patterns, would need specific calibration with the respective test results. The experiments used for calibration belong to the test series reported in [2]. Particularly, the specimens are GR3/k1.27/104, GR3/k1.64/104 and GR3/k2.18/104 with smooth grooves, whose main characteristics and test results are reported in Table 3, for more details see the original paper. The variable changing between the three specimens was the size of the (square) groove in which the NSM bar was embedded. This led to a transition in failure mode from splitting (for the two smallest sizes) to failure at the epoxy-concrete interface (for the specimen with the biggest groove). For the first two specimens, the low-level residual friction after failure was not included in the calibration, as the experimental post-splitting behavior had been inconsistent.

\section{Model Used for the Bar-Epoxy Interface}

A model originally developed to describe the bond mechanism between deformed steel reinforcement bars and concrete was used for the bar - epoxy interface. It was recalibrated to describe the new type of surface. A brief description of the model along with the chosen input data is reported as follows. For more details, see [14].

The model is of frictional type, using elasto-plastic theory to describe the relations between stresses and deformations. The yield surface is defined by two functions: $F_{1}$ describes friction, assuming that adhesion is negligible:

$$
F_{1}=\left|t_{t}\right|+\mu t_{n}=0
$$

and $F_{2}$ describes the upper limit at a pull-out failure. $F_{2}$ is determined from the stresses in the inclined compressive struts that result from the bond action, see Figure 7.

$$
F_{2}=t_{t}^{2}+t_{n}^{2}+c \cdot t_{n}=0
$$

The yield surfaces are shown in Figure 7. For plastic loading along the yield function describing the upper limit, $F_{2}$, an associated flow rule is assumed. For the yield function describing friction, $F_{1}$, a non-associated flow rule is assumed, for which the plastic part of the deformations is:

$$
d \mathbf{u}^{\mathbf{p}}=d \lambda \frac{\partial G}{\partial t}, \quad G=\frac{\left|u_{t}\right|}{u_{t}} t_{t}+\eta t_{n}=0
$$

Table 3. Test Specimens and Results Used for Calibration

\begin{tabular}{|c|c|c|c|c|c|c|}
\hline Specimen code & $\begin{array}{c}\text { Ultimate } \\
\text { load } \\
(\mathrm{kN})\end{array}$ & $\begin{array}{c}\text { Asymptotic } \\
\text { load } \\
(\mathrm{kN})\end{array}$ & $\begin{array}{c}\tau_{\text {avlu }}{ }^{* *} \\
(\mathrm{MPa})\end{array}$ & $\begin{array}{c}\tau_{a v 2 u}{ }^{* * *} \\
(\mathrm{MPa})\end{array}$ & $\begin{array}{c}\text { Groove } \\
\text { surface } \\
\text { cond. }\end{array}$ & Failure mode \\
\hline GR3/k1.27/104 & 11.22 & - & 7.03 & 9.87 & Smooth & Splitting \\
\hline GR3/k1.64/104 & 11.41 & - & 5.56 & 10.04 & Smooth & Splitting \\
\hline GR3/k2.18/104 & 13.07 & 7.90 & 4.78 & 11.49 & Smooth & $\begin{array}{c}\text { Epoxy-concr. } \\
\text { interface }\end{array}$ \\
\hline \multicolumn{8}{|c|}{ Average bond strength at the epoxy-concrete interface. } \\
$* * *$ Average bond strength at the bar-epoxy interface.
\end{tabular}




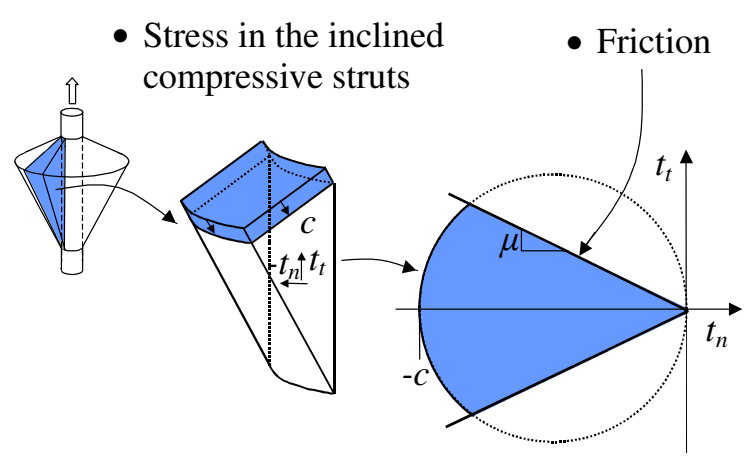

Figure 7. The yield surface of the model used at the bar-epoxy interface.

For the hardening rule of the model, a hardening parameter $\kappa$ is established, approximately equal to the applied slip. The variables $\mu$ and $c$ in the yield functions are assumed to be functions of $\kappa$.

Required input data for the bar - epoxy interface are the elastic stiffness matrix $D$, the parameter $\eta$ defined in equation (3) (tangent of the dilatancy angle), and the functions $\mu(\kappa)$ and $c(\kappa)$.

The elements $D_{11}$ and $D_{22}$ in the elastic stiffness matrix were influential on the stiffness of the first part of the bond-slip curve. As such, they were chosen (along with the analogous stiffnesses at the epoxy - concrete interface, see next section) to match the slope of the experimental bond-slip relationship. $D_{11}$ was also chosen to obtain a physically reasonable variation of the stresses along the reinforcement bar. The stiffness $D_{12}$ determines how large part of the normal stresses will remain after unloading. In order to calibrate this parameter, the shape of the descending branch in the load vs. displacement curve of specimen GR3/k2.18/104 was considered. In fact, when the specimen fails at the epoxy-concrete interface, the load starts decreasing and the state of stress at the bar-epoxy interface is relieved. Therefore, this interface is unloaded and the value of $D_{12}$ determines the magnitude of the normal stresses in this phase. If the absolute value of $D_{12}$ is too low, the load will not decrease down to the asymptotic value despite the appropriate choice of a hardening diagram for the epoxyconcrete friction coefficient. For three-dimensional modeling, the stiffness $D_{33}$ is also required to prevent the bar from rotating in the surrounding material. A value of $10^{10} \mathrm{~N} / \mathrm{m}^{3}$ was enough for this purpose, and was thus used in the analyses.

The parameter $\eta$, assumed to be constant for monotonic loading, was set to 0.1 . This value, along with the stiffnesses, had an influence on the stiffness of the bond - slip curve. Beyond a certain value of $D_{11}$ and $D_{22}$, such stiffness could only be increased by raising the value of $\eta$ (which was equal to 0.04 in the original model). 
In the original calibration of the model for steel reinforcement, the coefficient of friction, $\mu$, was assumed to vary during hardening from 1.0 down to 0.4 as the hardening parameter $\kappa$ (therefore, the slip) varied from 0 to $12 \mathrm{~mm}$. In the case of NSM reinforcement, splitting failure typically happens for very low values of slip (less than $0.5 \mathrm{~mm}$ ). Any choice of a $\mu(\kappa)$ function would have been arbitrary. Therefore, a constant value was attributed to $\mu$ at the bar - epoxy interface. Such value was chosen as 0.46 to match experimental and predicted ultimate loads of specimen GR3/k1.27/104.

The stress in the inclined compressive struts, $c$, was, as in the original model, chosen to be the same as the uniaxial compression curve of the epoxy in the plastic region. In the original model, this would allow to predict pull-out failure due to crushing of the concrete in front of the ribs of the steel deformed bar. However, the deformations on the surface of an FRP rebar, being made of resin, are much weaker than steel. Researchers studying bond of FRP bars in concrete have found that pull-out failure of ribbed FRP bars is governed by sequential shearing of the ribs and not by crushing of the concrete [8-9]. This is a fortiori valid when the FRP bar is embedded into epoxy, which typically has quite high values of compressive strength. In fact, pull-out failure by crushing of the epoxy was never encountered in the tests; accordingly, the yield line $F_{2}$ as previously defined was never reached in the analyses. Of more practical interest would be to define and calibrate a yield line corresponding to shearing of the ribs. However, this could not be done in the present investigation as no specimen had failed by this mechanism.

The values of the model parameters used in the analyses are summarized in Table 4. It must be kept in mind that these values are relative to the materials involved in the specimens on which calibration was conducted. Generally speaking, a smoother surface of the reinforcement bar would give lower values of the friction coefficient and lower stiffnesses in the elastic stiffness matrix.

Table 4. Values of the Calibrated Model Parameters.

\begin{tabular}{|c|c|c|c|c|c|c|}
\hline & $D_{11}\left(\mathrm{~N} / \mathrm{m}^{3}\right)$ & $D_{12}\left(\mathrm{~N} / \mathrm{m}^{3}\right)$ & $D_{22}\left(\mathrm{~N} / \mathrm{m}^{3}\right)$ & $\eta$ & $\begin{array}{c}\text { Cohesion } \\
\left(\mathrm{N} / \mathrm{m}^{2}\right)\end{array}$ & $\begin{array}{c}\text { Coeff. of friction } \\
\mu\end{array}$ \\
\hline Bar - Epoxy & $2.5 \mathrm{E}+13$ & $-2.2 \mathrm{E}+13$ & $2.5 \mathrm{E}+13$ & 0.1 & - & 0.46 \\
\hline $\begin{array}{c}\text { Epoxy }- \\
\begin{array}{c}\text { Concrete } \\
\text { (smooth } \\
\text { surface) }\end{array}\end{array}$ & $2.5 \mathrm{E}+13$ & - & $2.5 \mathrm{E}+13$ & 0.001 & $3.16 \mathrm{E}+06$ & Variable* $^{*}$ \\
\hline
\end{tabular}




\section{Model Used for the Epoxy-Concrete Interface}

For the epoxy-concrete interface, a Coulomb frictional model was adopted. The parameters needed for this model were the elastic stiffnesses $D_{11}$ and $D_{22}$, the cohesion, the friction angle and the dilatancy angle. It was also possible to specify a hardening diagram for the friction coefficient as a function of the plastic relative displacement.

The elastic stiffnesses had to be chosen as previously discussed for the bar - epoxy interface. It should be noted that the slip recorded in the experiments was the relative displacement between FRP bar and concrete, therefore, it included two different contributions relative to the slip between bar and epoxy and to that between epoxy and concrete. It was not possible to evaluate experimentally the relative magnitude of these two contributions. For this reason, the elastic stiffnesses for the two interfaces were chosen of comparable magnitude, in order for the load vs. total slip curve in the ascending part to match the experimental curve.

The ultimate load of specimen GR3/k2.18/104, failed at the epoxy - concrete interface, was particularly sensitive to the combination of the values of adhesion and initial friction, whereas the descending part of the load vs. slip curve was mainly influenced by the friction hardening diagram (and by the stiffness $D_{12}$ at the bar-epoxy interface discussed in the previous section). A higher bound for the adhesion was the experimental average bond strength at the epoxy concrete interface for specimen GR3/k2.18/104, equal to $4.78 \mathrm{MPa}$. This value was actually due to a combination of adhesion and initial friction, whose relative proportions needed to be calibrated. It was noticed that, for high values of adhesion combined with low values of initial friction, either the ultimate load of specimen GR3/k2.18/104 was overestimated or specimen GR3/k1.27/104 was erroneously predicted to fail at the epoxy - concrete interface. The best correspondence to the experimental results was given by lower values of adhesion combined with high values of initial friction.

The friction hardening diagram, $\mu(\kappa)$, was calibrated by matching the descending branch of the experimental load vs. slip curve and is shown in Figure 8. The tangent of the dilatancy angle $\eta$ was set to 0.001 . The values of the parameters are summarized in Table 4 .

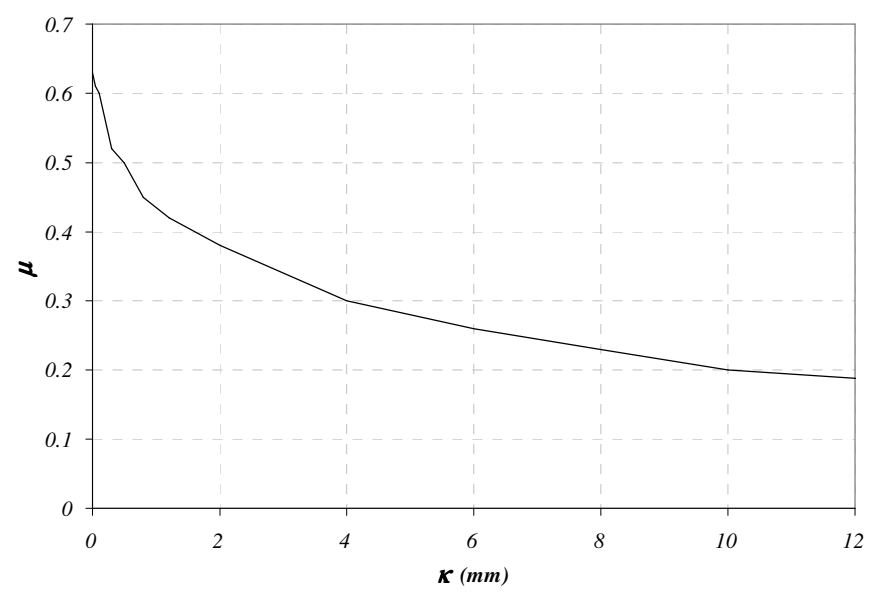

Figure 8. Function $\mu(\kappa)$ chosen for the epoxy-concrete interface. 


\section{Material Modeling}

Material properties of the specimens used for calibration were mostly obtained by testing. The properties of concrete, epoxy and GFRP bars were the same reported in the previous section on material properties. The modulus of elasticity of concrete was computed as $3950 \sqrt{f_{c}^{\prime}}, f^{\prime} c$ being the compressive strength, after [15].

The bar, epoxy, and concrete were all modeled with eight-node solid elements. The bar was modeled as linear elastic in tension. For the concrete and the epoxy, a rotating crack model based on total strain was used [13]. The hardening in compression was described for both materials by the expression of Thorenfeldt et al. [13]. For the concrete in tension, non-linear fracture mechanics was used, smearing out the deformation of one crack over a length corresponding to the size of one element, and using the curve by Hordijk et al. [13], to describe the tension softening behavior. The epoxy was assumed to have an elasto-brittle behavior, with no possibility to carry tensile stresses after cracking (zero fracture energy). The steel threaded bars used to react the load were modeled as "embedded" reinforcement, meaning that perfect bond between them and the concrete was assumed.

Meshing and analysis were conducted on half specimen, exploiting its symmetry. The mesh configuration is shown in Figure 9.

\section{Comparison with Test Results}

Figure 10 illustrates results of the analyses compared with the experimental curves, showing a reasonably good agreement. The stiffness of the theoretical curve is lower than the experimental one. This is probably due to having neglected adhesion at the bar-epoxy interface. However, the model is able to capture the change in failure mode corresponding to increasing groove depth, and the experimental failure load and load vs. slip behavior of the specimens.

Further research is certainly needed to assess the validity of the proposed model on a wider experimental database. Once the model is calibrated for a given set of materials, its predictions should be compared to experimental results independent from the ones used for calibration.

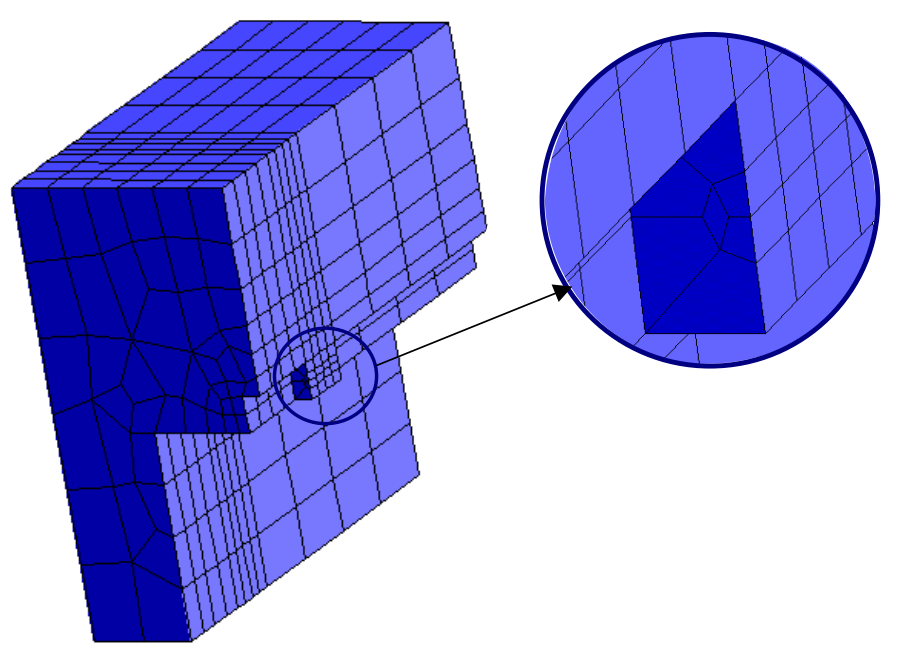

Figure 9. Typical meshing of half specimen. 


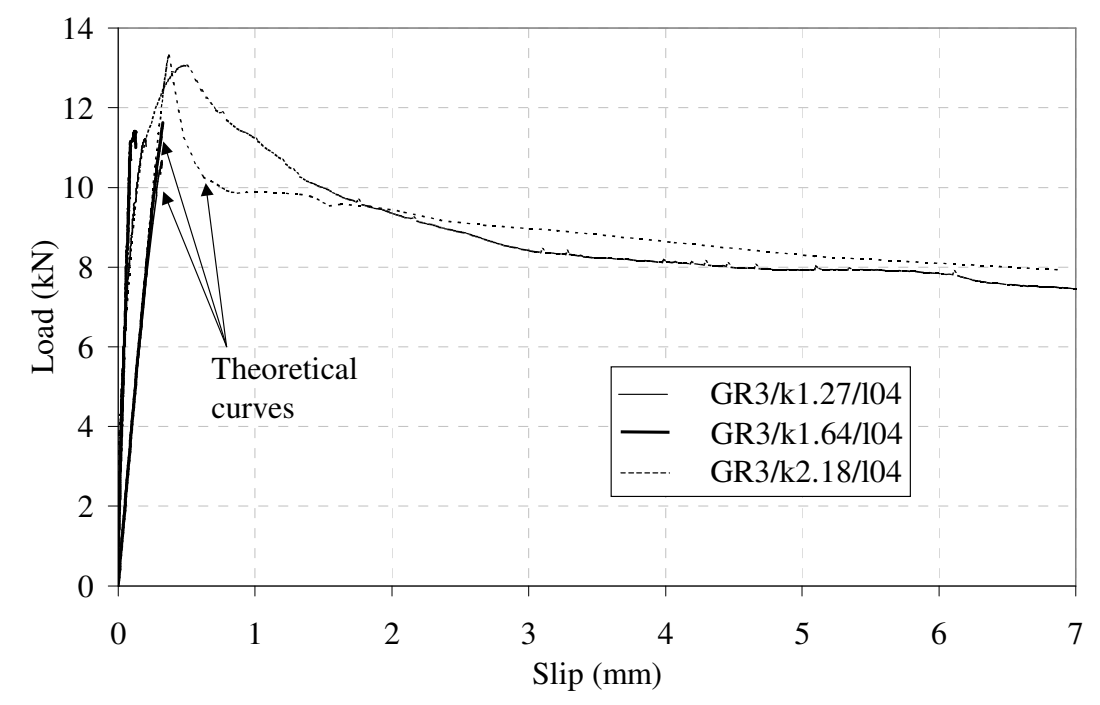

Figure 10. Comparison of theoretical and experimental results

\section{CONCLUSIONS}

A series of 34 specimens was tested to investigate the effect of groove-filling material, bonded length, groove size, and surface configuration of the bar on the bond performance of NSM FRP bars in concrete. By comparison with results of a previous test series, the effect of the groove surface condition was also examined. Finally, a global evaluation of the experimental data available from three extensive test programs was attempted. Although a brief summary of results might oversimplify the problem, it could be stated that: epoxy offers superior mechanical performance as groove filler with respect to cement paste; the most suitable types of bar for NSM applications are CFRP ribbed and CFRP spirally wound bars; a groove-sizeto-bar-diameter equal to 2.0 should be the optimal one; a smooth groove surface, although yields slightly lower local bond strengths, results in a more ductile bond - slip behavior and hence would be preferable.

An FE model was developed to study bond of NSM FRP reinforcement in concrete. Once calibrated on some experimental results, the model was able to capture the change in failure mode corresponding to increasing groove depth, and the experimental failure load and load vs. displacement behavior of the specimens. Its distinct feature is that, differently from most of the available FE models, it gives the bond-slip law of the joint as an output rather than input. Upon calibration and verification on a larger experimental database, it can be very useful to predict the behavior of RC members strengthened with NSM reinforcement, when bond is a critical aspect of the structural performance. 


\section{ACKNOWLEDGEMENTS}

The authors wish to acknowledge MAC Italia S.p.A. and FICES S.p.A. The first author would like to acknowledge the European TMR Network "ConFibreCrete", which supported her during a four-month stay at Chalmers University of Technology, and Prof. Ralejs Tepfers for helpful discussion.

\section{REFERENCES}

1. De Lorenzis, L. (2002), "Strengthening of RC Structures with Near-Surface Mounted FRP Rods", Ph.D. Dissertation, University of Lecce, Lecce, Italy, 289 pp, website http://ntlab-ambiente.unile.it/delorenzis

2. De Lorenzis, L., Rizzo, A., and La Tegola, A. (2002) "A modified pull-out test for bond of near-surface mounted reinforcement in concrete", Composites Part B: Engineering, Vol. 33, No. 8, December 2002, pp. 589-603.

3. De Lorenzis, L. (2003), “Anchorage length of near-surface mounted FRP bars for concrete strengthening - Analytical modeling", accepted for publication on ACI Structural Journal.

4. Tepfers, R. (1973), A Theory of Bond Applied to Overlapped Tensile Reinforcement Splices for Deformed Bars, Publication 73:2, Division of Concrete Structures, Chalmers Univ. of Techn., Gothenburg, Sweden.

5. CEB (1993), CEB-FIP Model Code 1990, CEB Bulletin d'Information No. 213/214, Lausanne.

6. van der Veen, C., (1990) “Cryogenic Bond Stress - Slip Relationship”, Ph.D. Dissertation, Delft University of Technology, Delft, The Netherlands, 111 pp.

7. De Lorenzis, L., and Nanni, A. (2002), "Bond of Near-Surface Mounted FRP Rods to Concrete", ACI Structural Journal, Vol.99 No.2, March-April, pp. 123-132.

8. Al-Zahrani, M.M. (1995), "Bond Behavior of Fiber Reinforced Plastic (FRP) Reinforcements with Concrete", PhD. Thesis, Department of Civil and Environmental Engineering, Pennsylvania State University, 263 pp.

9. Chaallal, O., and Benmokrane, B. (1993). Pullout and Bond of Glass-Fiber Rods Embedded in Concretes and Grout, RILEM Journal of Materials \& Structures, 26 (157), 167 175.

10. Guo, J. and Cox, J.V. (2000), “An Interface Model for the Mechanical Interaction Between FRP Bars and Concrete", Journal of Reinforced Plastics and Composites, v.19, n.1, 2000, pp. 15-33.

11. Bakis, C.E., Uppuluri, V.S., Nanni, A., and Boothby, T.E. (1998), "Analysis of Bond Mechanisms of Smooth and Lugged FRP Rods Embedded in Concrete", Composite Science and Technology, Vol. 58, No. 8, pp. 1307-1319.

12. Lundgren, K. (1999), "Three-dimensional modelling of bond in reinforced concrete". $\mathrm{PhD}$. Dissertation, Dept. of Structural Engineering, Chalmers University of Technology, Gothenburg, Sweden.

13. TNO Building and Construction Research (1998), "DIANA Finite Element Analysis, User's Manual release 7", Hague. 
14. Lundgren, K. and Gylltoft, K. (2000) "A model for the bond between concrete and reinforcement". Magazine of Concrete Research, Vol. 52, No. 1, pp 53-63.

15. Ahmad, S.M., and Shah, S.P. (1982), "Stress-strain curves of concrete confined by spiral reinforcement", Journal of the American Concrete Institute, v. 79, No. 6, pp. 484-490. 